\title{
BENUSSI AND THE HISTORY OF TEMPORAL DISPLACEMENT
}

\author{
Michele Sinico
}

In his Psychologie der Zeitauffassung (1913), Benussi dwells fully on the phenomenon of temporal displacement (Zeitverschiebung). This phenomenon undoubtedly merits special consideration because it represents experimental evidence, that a series of events, which are therefore in sequence on a physical time gradient, does not necessarily correspond to the series of events that inhabit phenomenal time. It can, in fact, be proven that a sequence of stimuli, sounds for example, such as the three sounds $a, b$, $\mathrm{c}$, become mixed up in their presentation order and they are perceived in the following sequence: A, C, B. Obviously, the phenomenon of temporal displacement has raised and continues to raise theoretical paradoxes which have no simple solutions.

At the beginning of the twentieth century gnoseological awareness was undeniably stimulating psychological research. Benussi devoted himself to contributing original ideas to the understanding of these paradoxes and continued to investigate on both an experimental and a theoretical level.

Experimental investigation of problems concerning the perception of temporal relationships characterised the Graz period. Benussi started his training in 1896 when he enrolled in the Faculty of Philosophy in Graz. ${ }^{1}$ There he worked in the laboratory that his mentor Alexius Meinong had founded in 1894 and that he supervised along with Stephan Witasek. Benussi showed both a methodological thoroughness and an intuitive engineering instinct for the preparation of experimental apparatus. The scientist of the time, in fact, often had to dirty his hands with "matter," and resort to home-made equipment for experimental work in order to achieve his personal research objectives. Indeed, as is well known, Benussi did not indulge in mere speculation but gave priority to empirical measurement in the firm belief that the main source of knowledge lay in facts and that therefore these facts had to be evaluated.

Nevertheless, the Triestine psychologist provided a decisive turning point in the study of temporal displacement even on the theoretical level. He introduced a phemonenological approach, which supplanted the dominant position occupied, at that time, by the undisputed fame of Wundt [Cattaruzza 1996].

\footnotetext{
${ }^{1}$ See, for example, [Antonelli 1994], 12.
} 


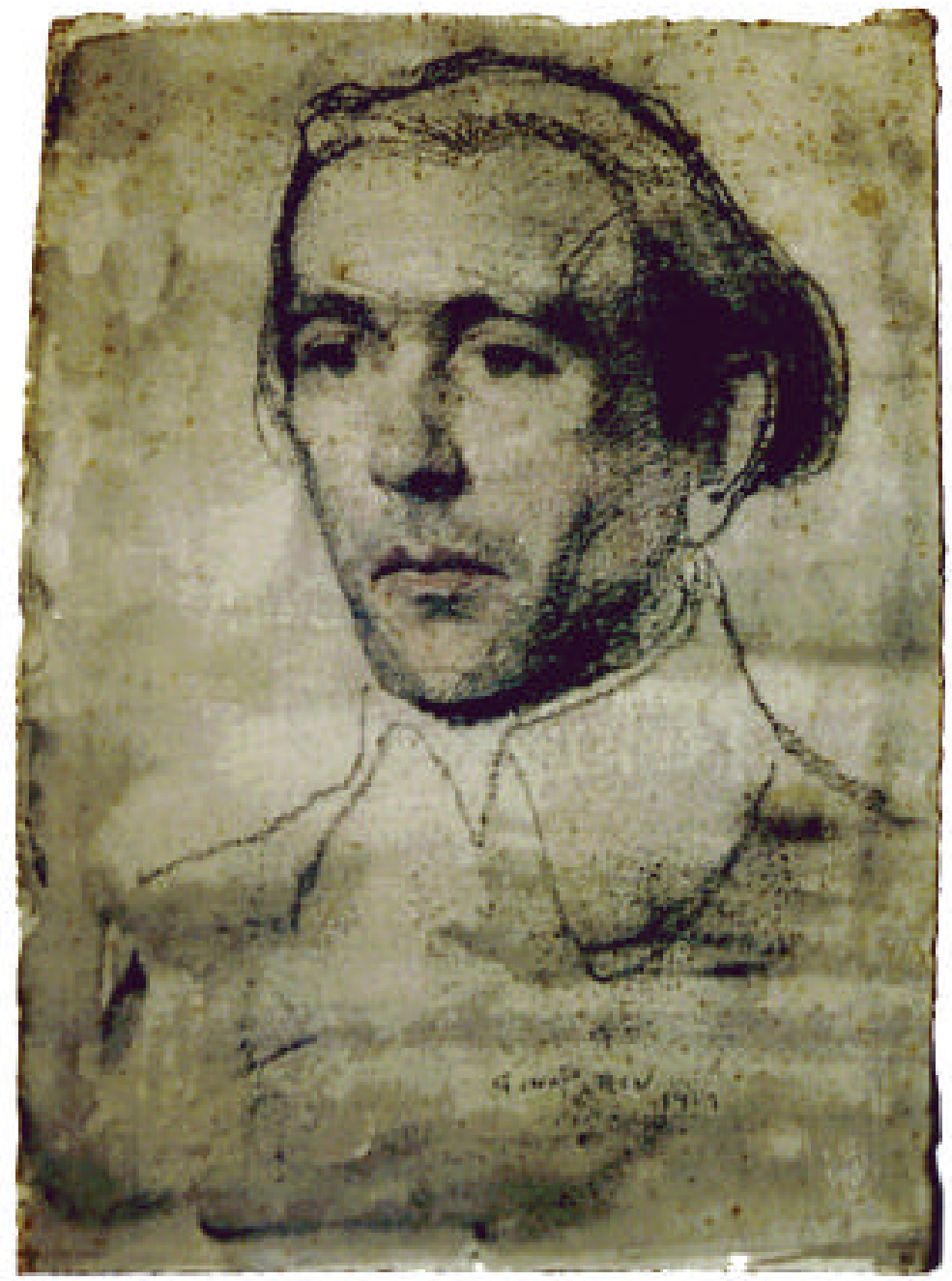

Figure 1. Vittorio Benussi, drawing by Gino Parin (Fondo Benussi Carteggio)

On the whole, therefore, Benussi's contribution to this field, which we shall shortly examine in greater detail, is of definite historic significance. But, for his contribution to be evaluated correctly, we must not consider his work in isolation. Instead, first we must briefly review the history of temporal displacement and describe the importance of his research within this context. 


\section{Greenwich 1795}

The eighteenth century is coming to an end as Gabriele Buccola (1883) reports in his historic reconstruction and, at the Greenwich Observatory, Maskelyne, the British Astronomer Royal, discovers that his assistant, Mr David Kinnebrook, has, for a year, been committing considerable errors in determining the transit time of celestial bodies on the Greenwich meridian. As is the custom, Maskelyne regularly notes the error in the third volume of the Observatory annals.

In the absence of an accurate chronometer, Kinnebrook has been obliged to use a method called eye-ear, which is necessary for calculating, precisely, to a fraction of a second the moment at which the star, moving very fast, passes over the meridian. The eye-ear method is as follows: the astronomical observer looks through the telescope in which is placed a vertical thread which acts as the spatial reference for the meridian. As the star crosses the area of the lens, the observer must listen attentively to the regular beats of a second pendulum and, at the same time, mark the two points in the star's transit (the two crosses in figure 2) that correspond to two beats: the one (A) before the meridian thread and the other (B) after the meridian thread.

Just a simple calculation of the ratio between time and distance measured will determine, to a close approximation, the fraction of a second in which the star moves across the meridian. This is illustrated below by figure 2 where, if it takes one second to go from A to B then it takes one-third of a second to go from A to $\mathrm{M}$.

Maskelyne is convinced that his assistant's continual errors are a result of negligence. So he dismisses him.

Nearly twenty years have passed. Bessell, an astronomer working at Königsberg, is glancing through the pages of the Greenwich Observatory annals where Kinnebrook's systematic errors are recorded. He soon suspects that these errors were not due to simple negligence and he looks into their cause. Bessell's suspicion that the application of the eye-ear method may vary from person to person is confirmed when he compares his own observation times with those of other competent colleagues. Thus, astronomy achieves a remarkable step forward: with his "personal equation," Bessell believes he can determine the degree of systematic error for each observer and so calculate correct times.

The debate involves well-known astronomers like Nicolai, who introduces discussion on the latent difference in the sensory organs, and Hartmann, who recalls the anticipatory role in the selective preference of one of two stimulations. Subsequent investigation reveals that observers can experience variations in their own calculations. This is because numerous objective factors come into play such as, for example, the dimensions of the star, its direction, its speed. Subjective factors may also contribute, such as 
the observer's training and his possible tiredness ([Buccola 1883]; [Sanford 1888]; [Vicario 1973]).

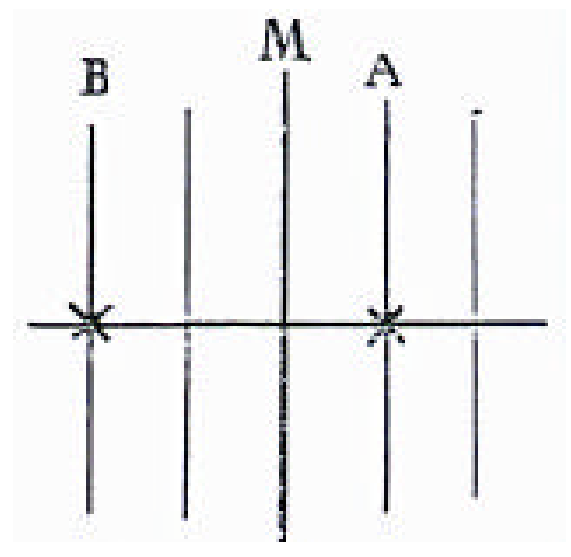

Figure 2. The vertical line, indicated by the letter $M$, represents the thread placed in the telescope and aligned to the Greenwich meridian. The two crosses indicate the two successive positions of the star as it moves from right to left, at the moment of the two successive beats of a second pendulum. The instant of passing of the celestial body is obtained by dividing the time by the distance [Buccola 1883].

\section{From astronomy to experimental psychology}

In 1840, new methods of observation are introduced that take account of reaction time. Reaction time is the time span between the presentation of a stimulus and the subject's response to it. Astronomers now realise that the error in calculating the moment of the stellar transit is due not only to the need to record two heteromodal stimuli: one visual stimulus (the transit of the celestial body between two reference points) and one auditory stimulus (the beats of the second pendulum), but also the concurrent mental operation of perception. The apparatus used becomes more sophisticated. Now, as soon as the observer sees the star near the reference meridian, he must press a button and at that precise moment a tachometer starts recording.

In the second half of the nineteenth century, photographic recording methods supplant those which involve subjective abilities. Psychology, however, continues to develop the instrumentation knowledge gained from astronomy. Thus, the method based on physiological time, or reaction time as it is coined for the first time by the physiologist Sigmund Exner, is refined by Hermann von Helmholtz and subsequently further perfected by the Dutch 
physiologist Frans Cornelis Donders. A little later on, it will form the cornerstone on which Wundt in his Leipzig laboratory, will base scientific psychology. At the end of the nineteenth century, the first Italian experimental psychologist Gabriele Buccola will follow in his footsteps. In 1883 , at the relatively young age of twenty-seven, Buccola publishes the volume "The Law of Time in the Phenomena of Thought." In this context, the word "time" refers to reaction time [Guardione 1936].

Astronomy bequeaths to the new-born psychology some unresolved, thorny problems that have already characterised a long and fascinating technical debate: predominantly, those perceptive errors that arise from heterogeneous sensory stimulation.

\section{The physiological explanations of Mach and Exner}

The nineteenth century is fast coming to a close and a physiological approach is becoming more popular in psychology. The most credible of the initial theories put forward to explain the phenomenon of temporal displacement is provided by Ernst Mach, a physicist, and Exner, a physiologist. These two scholars contend that the threshold of discrimination of two visual stimuli is much higher than the threshold of two auditory stimuli. Thus, temporal displacement is the logical consequence of the greater latency of visual sensation compared to auditory sensation or, rather, of the distinctive response of the physiological organ affected by the stimuli.

This explanation, however, glosses over the experimental evidence produced by James McKeen Cattell, that displacement is also possible within a single sensory modality. The American psychologist's interest in this phenomenon is undoubtedly interwoven with Wundt's research programme. In fact, Cattell has been one of his voluntary assistants in Leipzig for three years.

\section{Wundt's explanation of "attention"}

Wilhelm Wundt is the first to begin studying temporal displacement systematically. He coins the term "Zeitverschiebung" and, because he finds the physiological explanation unconvincing he conceives the so-called pendulum of complications (Complikationspendel), an instrument for the production of heteromodal stimuli suitable for the study of this phenomenon. This apparatus comprises a semicircular quadrant above which moves a needle, and a bell which produces a sound stimulus at the moment set by the experimenter (Fig. 3). 
The experimental subject must indicate the position of the needle on the quadrant at the precise moment when the sound event occurs.

In the very first experimental psychology laboratory, Wundt observes that most of the experimental subjects indicate that the position of the needle for the sound event is further on than it should be, even though the two stimulations are concurrent. In this case, it can be said that the auditory stimulus has undergone positive displacement. Moreover, Wundt notes that by changing certain parameters of attention, for example, increasing the velocity of the needle, even greater time lags are obtained in perceiving the sound event. These observations led Wundt to propose an attentionoriented explanation for temporal displacement.

In fact, for Wundt, a sensation is experienced only if attention is focused upon it. In the event of a plurality of sensations, which are, however, temporally very close to one another, then attention may combine them into a single event. This is, however, only possible when the two sensations are similar or when they belong to the same sensory field, whereas it is no longer true if they belong to different sensory modalities. If the sensations are heterogeneous, the focus of attention must in fact move from one to the other, thus producing a subjective sequential effect. On the other hand, within the same sensory sphere, the displacement phenomenon can be explained by considering the different intensities of the stimuli: attention is directed first towards the more intense stimuli then shifts to those less intense ([Vicario 1976] and [1997a]).

\section{Further contributions}

Wundt's experiments stimulate many scholars to undertake research. These include talented experimental scientists who underline that the phenomenon of temporal displacement can depend a plurality of factors.

After being a student of Wundt at Leipzig, Albert Michotte (1912) reproduces the Wundt experiments demonstrating the effect of the subject's approach: if the attention is focused on the auditory stimulus, the displacement (of the sound) is negative whereas if the attention is focused on the visual stimulus, that is, the needle, then the displacement (always of the sound) is positive. In Florence, Enzo Bonaventura [Bonaventura 1928] emphasises that the visual stimulus, which starts before the auditory stimulus, produces a disturbance factor: that of waiting. 


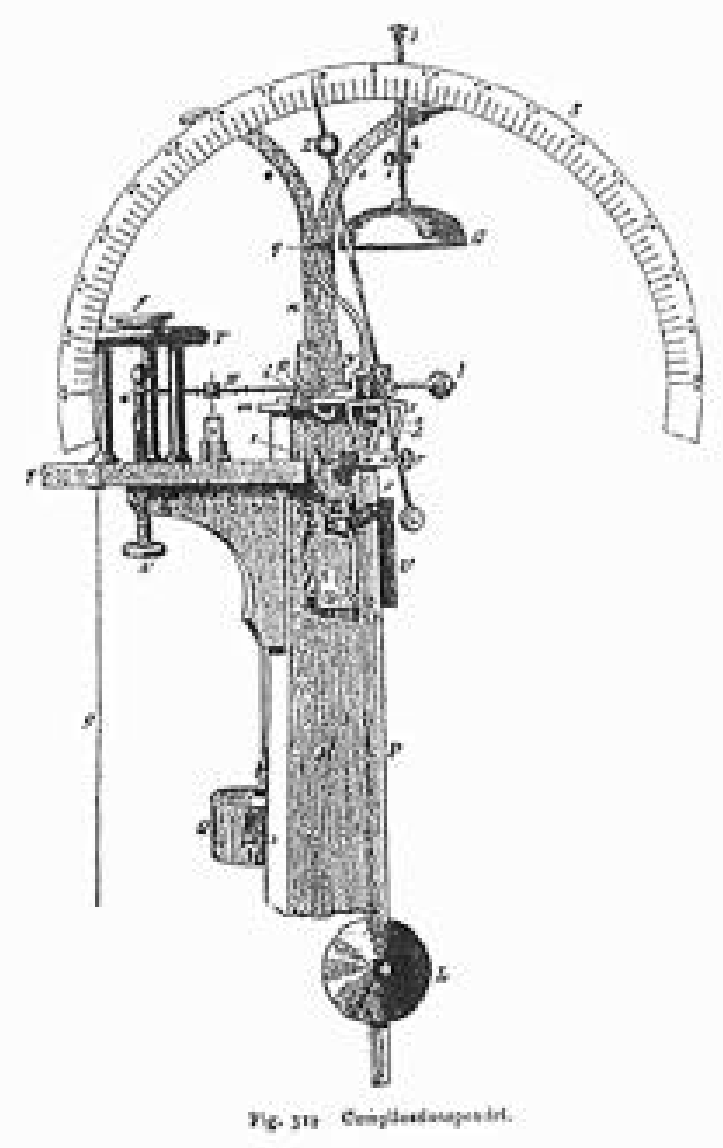

Figure 3. Wundt's pendulum of complications. The needle (Z) moves with angular motion. At a given moment of motion the bell rings $(\mathrm{G})$. The experimental subject has to indicate the position of the needle on the graduated semicircle $(\mathrm{S})$ at the moment the bell rings [Wundt 1893].

[Pauli 1911], however, demonstrates definitively that attention alone cannot explain this phenomenon. In fact, if two stimuli are projected concurrently on the retina, the stimulus which falls on the foveal area is perceived before the stimulus which falls on the peripheral area. And this happens even if the observer is expecting to see the peripheral stimulus first.

\section{Benussi and temporal displacement}


Meanwhile, at Graz, Benussi is not satisfied with the current explanations. The Triestine psychologist uses terminology which is sometimes technical: for example, calling temporal displacement, the phenomenon of "inadequate temporal placement" and noting that the phenomenon in question must not be ascribed to variations of a "sensory function" (in other words to the velocity of sensations) as Exner has claimed, or to the shift of attention as Wundt has maintained.

Temporal phenomena are investigated by systematic and meticulous experimentation that produces a considerable volume of data. These data are reported in the 1913 volume: Psychologie der Zeitauffaussung. However, on reading the text, it is clear that the experimental work has been influenced by the Graz School. The Triestine psychologist, in fact, adopts the Meinongian argument to overturn, theoretically, the formulation of the problem of temporal displacement. The psychic present is not punctual but has an extension which can have a premonition of subsequent matter, of specific elements arranged in sequence. Meinong writes: "it can, therefore, be maintained that objects of higher order can only be represented by means of non-discrete contents; while lower order objects, so far as they are temporarily distinct, must appear in a contemporary representation, although of course not as contemporaries." ${ }^{2}$ As an example, the notes of a melody which follow each other in a particular order are heard simultaneously because they fall within a single perceptive event. However, this is not why they are heard as simultaneously present [Albertazzi 1999].

In the same manner, when Benussi says: "introspection does not allow us to perceive any plurality of acts of observation or attention, unless the intervals are very large, ${ }^{\prime 3}$ he is saying that if the stimuli to be located fall within a brief interval of time, they are not perceived individually, each in its own specific position, but rather as a whole.

In this definition, the phenomenological position of the Gestaltpsychologie of the Graz School appears evident. It favours the study of the articulation of elements rather than the analysis of these taken in isolation. This position is, in fact, directed towards describing perceptual events and to setting up those laws that govern the formation and the stability in time of such events in their unitarity.

The experiment that Benussi uses to study displacement requires the setting up of an ad hoc apparatus. Figure $4 \mathrm{c}$ illustrates a rotating disc $\left(\mathrm{S}_{2}\right)$, as shown in figure $4 \mathrm{a}$, mounted on a structure. This disc has one hole (pr) on one half and eleven holes on the other half. Ten of these eleven holes are covered by patches (SS). When the disc S2 turns, the two holes that remain uncovered coincide at a certain moment with the holes $\mathrm{P}$ and $\mathrm{P} 1$ on the fixed screen M1, clearly shown in figure $4 \mathrm{c}$. At this precise moment, two

2 [Meinong 1899], 448.

3 [Benussi 1913], 371-72. 
luminous points appear on the screen as a result of the light coming from an arc lamp, or rather from an arc that is struck between two carbon rods connected to an electric power line. On the rotating disc S2, the radial distance of the hole pr is different from that of the one hole on the other half that is left uncovered. A different distance, the speed of rotation of the disc being known, represents a specific different temporal interval between the appearance of the two luminous points on the screen.

As a result of observations arising from experimentation, Benussi focuses his interest on an apparent contradiction. On the one hand, as stated above, a unitary perceptive event has been postulated within fixed temporal limits. On the other hand, however, phenomena of localisation take place within this perceptive event or, in other words, the pre- and post-relationships between the stimuli which form the sequence are experienced.

One of Benussi's manuscripts states "Within given limits, $60-80 \mathrm{msec}$, the second sensation ( a point that lights up to the right) can be perceived as the first temporal sensation. This can, therefore, be said to be a real temporal inversion (which has absolutely nothing to do with W. Wundt's complication experiments!)."

In Wundt's complication experiments, in fact, the sound of the bell always occurred during the movement of the needle. As a consequence, the sound could not appear before or after the visual event. Thus, in the chapter on "Temporal displacement of given visual impressions" of Psychologie der Zeitauffassung, Benussi denounced these experiments and shifted the focus of theoretical attention from the stimulus to the Gestalt, that which is immediately given to phenomenal experience.

First of all, he specifies that these inversion phenomena, as for example resulting from the different intensity of the two stimuli in question, the two lights in fact, do not depend: "on the changes in the intensity of the stimulus as such, but it must be borne in mind that more rapid manifestation of the light, that is, a greater emphasis (Auffälligkeit), is usually accompanied by a greater intensity of the luminous stimulus itself." ${ }^{5}$ This means that it is the emphasis and not the stimulus that determines the effects, although often with the concurrent change in the physical intensity of the stimulus.

He goes on to provide the values for temporal thresholds, adding however, a basic condition: "the smallest temporal objective distances, to which an awareness of sequence corresponds, are traditionally defined as temporal thresholds. They vary between $2-50 \mathrm{msec}$ for similar sensations (that is homogeneous) and between $60-160 \mathrm{msec}$ for dissimilar sensations (that is heterogeneous). It must however be underlined that these definitions do not apply to temporal thresholds but to sequential thresholds. The nature of a threshold is not, in fact, defined on the basis of the properties of the

${ }_{5}^{4}$ [Benussi 1926], file 56.

5 [Benussi 1913], 398. 
objective changes (of the change in the stimuli) to which it is of course linked but rather in relation to the quality and the characteristics of the phenomena perceived, that is the objects.

Figure 4. An instrument for the study of temporal displacement in the visual modality. Figures B and C, respectively, illustrate the frontal and lateral views of the disc-support
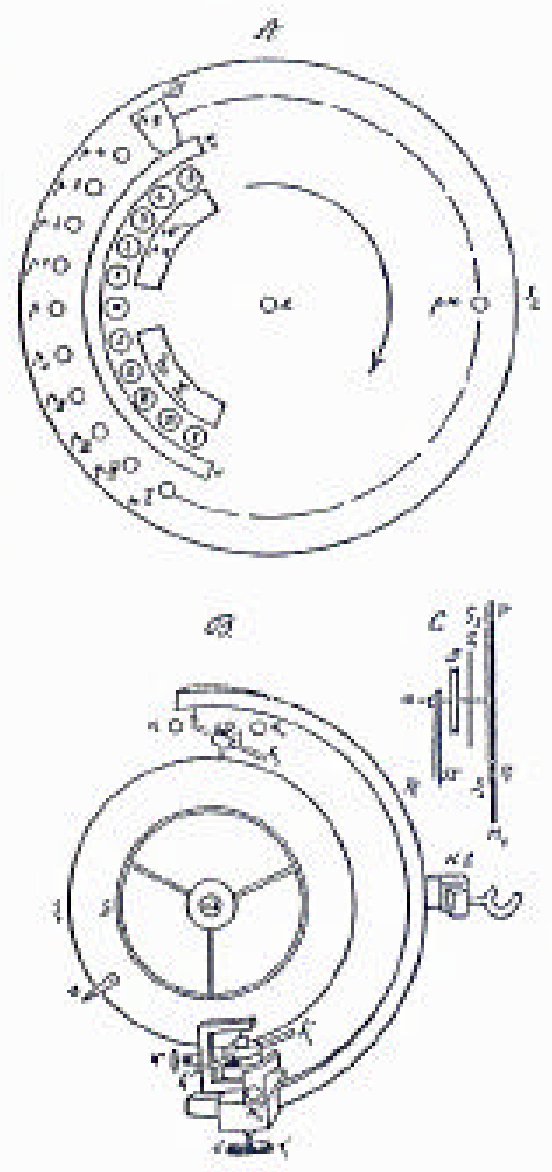

structure, on the rear side of which is projected a light beam. On the disc in figure A, one hole (pr) is shown on the left and eleven holes $\left(\mathrm{p}_{5}, \mathrm{p}_{4} \ldots, \mathrm{p}_{\mathrm{v}}\right)$ on the right. Out of the eleven holes only one is not covered by a patch (SS). The time that elapses between the passage of light through the first and the second hole is given by the ratio between the speed of rotation of the disc and the radial distance between the two holes [Benussi 1913].

Therefore, we do not perceive a temporal path but a sequence. Of course, we are always at liberty to infer from the sensation of the sequence a passage of time, even of minimal duration. But what is immediately perceived is not 
a passage of time, it is not temporally characterised, and therefore even the objective temporal path is not a temporal threshold." 6 Here Benussi underlines that the sequence is an immediate fact whereas the temporal path is implicit in the sequence but requires a perceptual act.

In addition, he adds, referring back explicitly to the theory of the psychic time of presentness of [Stern 1897]: "Research of this kind together with the definition of the thresholds of sequence, makes it possible to determine the subjective duration of the presence: that temporal distance amongst phenomena within which they are perceived as concurrent.",

However, let us now return to solving the above mentioned apparent contradiction by means of an articulate response.

The unitary perceptive event is a structural whole (a Gestalt). Within this structure the element which is distinguished by a sort of emphasis ( $A u f$ fälligkeit) or rather, the one that is most impressive, would have temporal precedence. Therefore, the location of the events depends on the outcome of the interaction between the constituent elements in the resultant structure.

In the same manuscript he expresses the following: "it is a question of the influence of figurative elements on temporal placement. ... elements relative to the subjective behaviour and on which the above temporal inversion may depend. It is always formal elements which favour the inversion, obstruct it, exclude it or undoubtedly determine it." 8

In the final analysis, Benussi's notable contribution to the study of temporal displacement consists in his having definitively refuted the explanations, although they had already been revealed as inadequate, that are based either on the speed of sensations or on the orientation of attention. Secondly, of having defined a temporal magnitude within which the phenomenon takes place and, finally, of having introduced the concept of structure in the perception of temporal events [Vicario 1976].

\section{Rubin's auditory experiments}

It is 1949 and Edgar Rubin is carrying out experiments on auditory temporal displacement. These experiments signal a clear improvement from the point of view of strict experimental control. However, on the theoretical front, there is no corresponding progress. Indeed, it means a step backwards in that premises that have already been firmly confuted are once again being developed. We shall now examine these experiments in detail.

\footnotetext{
${ }^{6}$ [Benussi 1913], 402.

${ }^{7}$ [Benussi 1913], 403.

8 [Benussi 1926], file 56.
} 
Rubin uses brief sounds as stimuli: a hammer blow and a muffled bell ring. The most important of his experiments are those in which he adopts three stimuli in sequence (a hammer blow, a pause of $294 \mathrm{msec}$, a bell ring, a pause of $36 \mathrm{msec}$, a hammer blow). By adopting three stimuli, in fact, the influence of attention is to a large extent reduced; while, on the contrary, the functional reactions between the processes of mechanical elaboration of the stimuli emerge, between the moment of peripheral excitation, and the moment of their qualification as perceived events [Rubin 1949].

The sequence of three stimuli gives rise, in certain cases, to a negative displacement of the second hammer blow: the two hammer blows are heard first, before the bell ring. Rubin's explanation emphasises the psychophysiological process which, with the second blow of the hammer, undergoes an acceleration because the mechanism is "already ready," after having been mobilised by the first equal blow of the hammer. Consequently, phenomenologically, the second hammer blow comes before the ring of the bell. Moreover, Rubin underlines that the perceived sequence has a character of reality: the subject, in fact, does not experience it as an illusion.

Theoretically, Rubin embraces an explanation that had already been proven false thirty years before: that is, the speed of sensations. However, when he observes that two of the stimuli in the sequence enjoy the privilege of being equal he is unintentionally corroborating Benussi's intuition. It is, in short, the relationship of similarity between the elements of the sequence that imposes the arrangement of the order perceived.

\section{Stroud and Fraisse}

It is in the early fifties when Stroud's theory of "moments" of psychological time starts to take shape. Psychological time, for this pupil, is to have a discontinuous structure. The nervous system, in fact, would produce a scanning, every "moment" of which would last approximately $100 \mathrm{msec}$. If two events occurred at the same "moment" they could interact and not correspond to the sequence given in the physical gradient. This theory, however, breaks down in the face of completely intuitive objections. Indeed, if there were no synchronisation between the central scanning and the physical events, then the two above mentioned events (let us take as an example Rubin's experiment, or rather, the bell ring and the second hammer blow) could sometimes fall within a single "moment" while, on the other hand, from time to time they would appear in two adjacent "moments", thus giving rise to a perceptive result which is different every time [Vicario 1976].

One of Henri Pieron's students takes a completely different standpoint: Paul [Fraisse 1957] who represents, in fact, one of the most outstanding 
authorities on psychological time. In agreement with his mentor, he believes that heterogeneous stimulations could give the impression of nonsequentiality. This is in agreement with an old idea put forward by [Guinzburg 1928], who upheld the theory of a conscience of nonsimultaneity. Fraisse, however, adds that the perception of simultaneity would be possible whenever the stimuli show such similarity as to be able to be integrated or unified.

\section{Vicario and the unit of psychological time}

In the meantime, however, Stroud's theory finds no acceptance at the Institute of Psychology of the University of Trieste. The Institute is under the directorship of Gaetano Kanizsa, a student of Cesare Musatti, who carried on the experimental-phenomenological-capability of Benussi. One of the students is, in fact, Giovanni Vicario, who is studying a new sequence of temporal displacement in an auditory field: la $(100 \mathrm{msec})$, white noise (35 $\mathrm{msec})$ and sol $(100 \mathrm{msec})$. The experiment consists of cutting up lengths of magnetic tape on which different sound frequencies and white noise have been recorded. The tape, re-composed according to the sequence to be followed, is then rewound. Then, a tape recorder is used to reproduce the stimulus sequence. The experimental subjects claim the white noise is displaced positively because they can hear it after the sequence of the two sounds la-sol.

The explanation unequivocally calls to mind Benussi's theory: the perceptive act of the three stimuli is unitary, but it favours the affinity between the two notes so as to anticipate the second one or, if looked at from a different perspective, so as to postpone the white noise. Experimental variations of this sequence point out that those factors responsible for temporal displacement are structural, such as the precedence of more acute sounds, the tonal distance within the sequence, the similarity between the lateral sounds, etc. All these variations are qualities of comparison between the actual elements in the sequence, or in the structure [Vicario 1973].

The phenomenon of temporal displacement is, therefore, established by experimental proof, together with other well-known phenomena recorded in literature, such as the tunnel effect, the brake effect, the acciaccatura effect, etc., which are contrary to the theory which speaks of a rather special brief unit of time, the "moment" of $100 \mathrm{msec}$. Moreover, all these phenomena have different temporal structures, that is times of realisation. Therefore, Stroud's fixed length of "moment" only exists when exclusively referring to the actual structure of single events. 


\section{New models}

The study of temporal displacement, like that of the psychology of time, undergoes a period of stagnation. Nevertheless, research of a cognitive nature recognises the existence of this phenomenon in the understanding of the spoken language. The explanations of the discrepancy that exists between the events in the physical gradient and those in the psychic gradient are attributed to physiological processes of the nervous system, thus reviving Rubin's theory. [Ladefoged and Broadbent 1960] devise an experiment in which they ask the subjects to listen to the following sentence: "John that was the boy that had a top" and to identify a sound, a "click," which is superimposed at a certain point in the sentence. Results show that the sound is slightly displaced to before the beginning of the word over which it is superimposed. Ladefoged and Broadbent thus maintain that they have demonstrated the existence of a mental process which stores incoming information and which is commanded to process not individual, single, sounds, but fairly large chunks of sound. Indeed, as [Vicario 1997a] claims, we cannot tell, strictly speaking, whether just the sound is displaced negatively or whether it is the whole of the sentence which undergoes positive displacement.

Another very fashionable model, which attempts to explain temporal displacement in the visual field, is that of a neuro-physiological nature. According to the model of Reichardt's "Elaborated Reichardt Detector" [Reichardt 1961], which is shown in figure 5, there are, in fact, two groups of nerve cells which act as detectors of motion, each one of them recording a position of the object. A person responds, comparing the signals recorded by the detectors, only after the second detector has picked up the signal. If it were this physiological mechanism that controlled the perception of movement, then the reply should reveal delays of even as long as $200 \mathrm{msec}$ as far as the physical occurrences are concerned, that is, the time needed to enable the person to compare both signals.

It could be argued that it is difficult to attribute delays of such magnitude to the rapidity with which our organism responds to events that are obtained from the environment. Perceived movement must not be confused with the motory reaction to physical movement [Vicario 1997a]. However, research conducted by [Libet 1987] supports this model. Libet, in fact, uses a local anaesthetic so that the patient remains conscious during neurological surgery. In this way the research worker can compare the response to the stimulation of the somato-sensorial cortex, which produces a sensation that corresponds to the stimulation of the hand, with the stimulation of the hand itself. Results show that tactile stimulation of the hand precedes that of the cortex. It is thus demonstrated that motor response takes less time than the 
conscious recognition of events. These recognitions of events combine so as to recompose facts relating to the past, the present and the future. Coming back, therefore, to the displacement of an internal element within an auditory sequence, the position of the displaced sound would, therefore, be established only after all three sounds have been heard ([Vicario 1978], [1997a]).

\section{New reductionism}

The historical importance of modern neuro-physiological models can be evaluated on the basis of the epistemological assumptions that underpin this research. A recent attempt to do so can be seen in [Vicario 1997b].

Among the various questions that these models pose on a theoretical plane, there is a basic one of paramount importance. It is precisely this: it can be said that it is important and useful to know how the brain works, since it is clear that in observing objects (or events) the brain, seat of mental functions, works in a certain manner. But, even with this knowledge, it is not possible to explain the phenomenological properties of the objects observed. In fact, it is not possible to translate the properties of objects under observation into neuro-physiological mechanisms or, in other words, into the mental functions of the observation itself. For a logical analysis of the psycho-physical schema, reference must be made to [Bozzi 1989] who demonstrates that all the stages that occur between the physical object and the perceived object always remain important in themselves but not necessary to the final perceptive result.

The study of temporal displacement appears to elude new models [Bloch 1990], which are concerned with psychological time. These models assume as a basic premise, the existence of a mental "calculator," based on cycles of the physical organism, like, for example, circadian rhythms. Therefore, the problem simply shifts to the reading of the calculator. Concerning the order in which events undergoing temporal displacement occur, the clearest hypothesis, even today, remains the descriptive explanation of phenomenological nature, advanced by Benussi. 


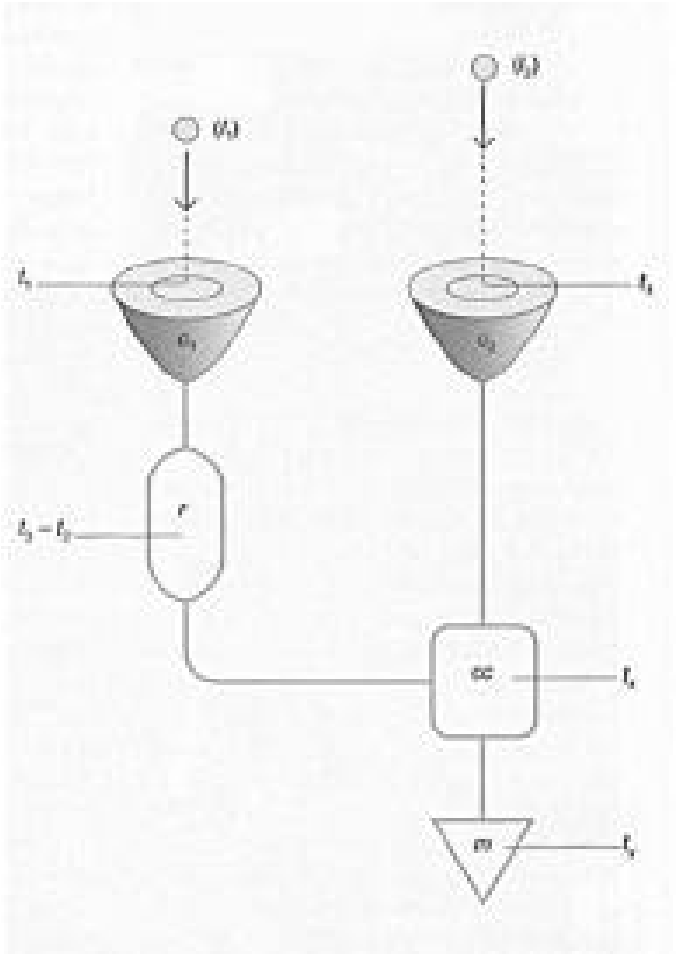

Figure 5. The Elaborated Reichardt Detector. In the figure, 11 and 12 represent stimuli; $\mathrm{c} 1$ and $\mathrm{c} 2$ the receptive fields; $r$ the delaying circuit of the first stimulus; $c c$ the control circuit; $m$ the perceptive response.

\section{Parte objecti perception}

The road to emancipation of the science of spatial-temporal objects can be traced by means of the Meinongian theorisation [Meinong 1899]. Bozzi followed in Meinong's footsteps: "No one ever sees stimuli, by definition. But sensations (if we insist on wanting to use this term to define certain segments of direct experience which are open to observation by one or more observers) are verifiable facts, likewise by definition." "9 It can, therefore, be inferred that for psycho-physics: "what visibly happens is considered to be the effect of an indirectly defined cause... Stimuli are (ideally) bits of physical reality, whereas colours, sounds and the tessera of any mosaic are pieces of the real world; it is unsafe to try and explain the latter as an effect of the former and it is a mistake to think that the former are constituent

\footnotetext{
${ }^{9}$ [Bozzi 1996], 287.
} 
elements of the latter." ${ }^{10}$ Physical reality cannot be deemed the cause of the phenomenological world. It follows that cognitive research must therefore be founded on a different basis: "An observable fact certainly has its constituent elements, it is sufficient to examine it in detail to see how they are involved; an observable fact certainly obeys laws, so much so that we do not live in a chaos of sensations, but in the midst of things to which we can relate. Therefore, laws exist which regulate the relationship between constituent elements and these laws must in some way influence the explanation of how things are made."11 These points indicate a crucial theoretical advance because Meinong - continues Bozzi: "founded the science of objects, and every science of the observable in general, on epistemologically independent bases."12

As described above, Benussi translated this advance into the experimental study of time. However, only with the emergence of experimental results could the boundaries of the theoretical consequences be extended. The study of temporal displacement, in fact, forced Meinong, as Bozzi recalls, to accept the concept of "time of presentness," which had already been introduced by [Stern 1897], or rather, that temporal duration, therefore not precise, which indicates the becoming by characterising in a measurable duration of time our elusive contact with the world.

\section{Conclusion}

To summarise, the phenomenon of temporal displacement came to light through astronomy and it formed one of the first problematic issues of experimental psychology. It represented, in fact, a typical case of dissimilarity between the characteristics of physical reality and those of perceptive reality.

Nearly a century ago Benussi had, with deep philosophical awareness, grasped the complexity of the phenomenon. Such awareness was derived from his understanding of the sophisticated Gegenstandstheorie that evolved from the Graz theory. Moreover, with great experimental skill, he succeded in formulating and describing the controlled situations in which such a discrepancy manifested itself.

Therefore, current research, which is carried out within the difficult discipline of the 'psychology of time,' cannot ignore his pioneering contribution.

\footnotetext{
${ }^{10}$ [Bozzi 1996], 287-88.

${ }^{11}$ [Bozzi 1996], 288.

12 [Bozzi 1996], 288.
} 


\section{References}

[Albertazzi 1999] L. Albertazzi, "Enzo Bonaventura: strutture temporali e ontologia," in L. Albertazzi, G. Cimino and S. Gori-Savellini, eds., De Sarlo e il laboratorio fiorentino di psicologia, Giuseppe Laterza ed., Bari.

[Albertazzi 1993] L. Albertazzi, "Eventi sonori," in L. Albertazzi, ed., La percezione musicale, Guerini, Milan.

[Antonelli 1994] Die experimentelle Analyse des Bewusstseins bei V. Benussi, Rodopi, Amsterdam.

[Benussi 1913] V. Benussi, Psychologie der Zeitauffassung, Winter, Heidelberg.

[Benussi 1926] V. Benussi, Schede riassuntive delle opere di Benussi, manuscript, Fondo Benussi carteggio, 1926.

[Block 1990] R.A. Block, Cognitive models of psychological time, Lawrence Erlbaum Associates, Hillsdale.

[Bonaventura 1929] E. Bonaventura, Il problema psicologico del tempo, Società anonima Istituto editoriale scientifico, Milan.

[Bozzi 1996] P. Bozzi, "Higher-order objects," in L. Albertazzi, M. Libardi and R. Poli, eds., The School of Franz Brentano, Kluwer, Dordrecht.

[Bozzi 1989] P. Bozzi, Fenomenologia sperimentale. Il Mulino, Bologna.

[Buccola 1883] G. Buccola, La legge del tempo nei fenomeni di pensiero, Fratelli Dumolard, Milan.

[Cattaruzza 1996] S. Cattaruzza, "The Philosophy of Psychology by Benussi," in W. Baumgartner and others, Phenomenology and Cognitive Science, Röll, Dettelbach.

[Exner 1875] S. Exner, "Experimentelle Untersuchung der einfachsten psychischen Processe," Plugers Archiv für die gesamte Physiologie 11, 403-32.

[Fraisse 1957] P. Fraisse, Psychologie du temps, Presses Universitaires de France, Paris.

[Guardione 1936] F. Guardione, Scritti di Gabriele Buccola, Arti Grafiche Castiglia, Palermo.

[Guinzburg 1928] L. Guinzburg, "È possibile l'apprendimento di sensazioni eterogenee come perfettamente simultanee?," Archivio Italiano di Psicologia 4, 103-14.

[Ladefoged and Broadbent 1960] P. Ladefoget and D.E. Broadbent, "Perception of sequence in auditory events," Quarterly Journal of Experimental Psychology 12, 162-70.

[Libet 1987] B. Libet, "Consciousness: Conscious Subjective Experience," Encyclopaedia of Neuroscience, Birkhäuser, George Adelman, vol. 1.

[Meinong 1899] A. Meinong, "Ueber Gegenstände höherer Ordnung und deren Verhaltniss zur inneren Wahrenehmung," Zeitschrift für Psychologie und Physiologie der Sinnesorgane 21, 182-272.

[Meumann 1893] E. Meumann, "Beiträge zur Psychologie des Zeitsinns," Philos. Stud. 8, 431-519.

[Michotte 1912] A. Michotte, "Nouvelles recherches sur le simultaneité apparente d'impressions disparates périodiques," Ann. Inst. Sup. Philos. 
[Pauli 1911] R. Pauli, "Über die Beurteilung der Zeitofdnung von optischen Reizen," Arch. Geg. Psychol. 21, 132-218.

[Reichardt 1961] W. Reichardt, "Autocorrelation, a Principle for the Evaluation of Sensory Information by Central Nervous System," in W.A. Rosenblith, ed., Sensory Communication, New York, Wiley.

[Rubin 1949] E. Rubin, Experimenta psychologica, Copenhagen, Munksgaard.

[Sanford 1888] E.C. Sanford, "Personal Equation," The American Journal of Psychology 2, 38.

[Stern 1897] L.W. Stern, "Psychische Prasenzzeit," Zeitschrift für Psychologie und Physiologie der Sinnesorgane, 13, 325-49.

[Stroud 1955] J.M. Stroud, "The fine structure of psychological time," in H. Quaster, Information Theory in Psychology, Free Press, Glencoe.

[Vicario 1973] G.B. Vicario, Tempo psicologico ed eventi, Giunti Barbera, Florence.

[Vicario 1997a] G.B. Vicario, "Il tempo in psicologia," Le Scienze, 43-51.

[Vicario 1997b] G.B. Vicario, "Discutendo di coscienza," Giornale Italiano di Psicologia 24, 67-81.

[Vicario and Zambianchi 1998] G.B. Vicario and E. Zambianchi, La percezione degli eventi, Guerini, Milan.

[Wundt 1911] W. Wundt, Grundzüge der physiologischen Psychologie, Engelmann, Leipzig.

Dipartimento di Psicologia Generale

v. Venezia, 8; 35131 Padova

e-mail: sinico@psy.unipd.it 